\title{
Distortional Buckling Analysis of Steel-Concrete Composite Girders in Negative Moment Area
}

\author{
Zhou Wangbao, ${ }^{1,2}$ Jiang Lizhong, ${ }^{2}$ Kang Juntao, ${ }^{1}$ and Bao Minxi ${ }^{3}$ \\ ${ }^{1}$ School of Civil Engineering and Architecture, Wuhan University of Technology, Wuhan 430070, China \\ ${ }^{2}$ School of Civil Engineering, Central South University, Changsha 410075, China \\ ${ }^{3}$ School of Civil Engineering, University of Birmingham, Birmingham B15 2TT, UK \\ Correspondence should be addressed to Kang Juntao; jtkang@163.com
}

Received 4 July 2014; Revised 9 October 2014; Accepted 9 October 2014; Published 10 November 2014

Academic Editor: Ting-Hua Yi

Copyright (C) 2014 Zhou Wangbao et al. This is an open access article distributed under the Creative Commons Attribution License, which permits unrestricted use, distribution, and reproduction in any medium, provided the original work is properly cited.

\begin{abstract}
Distortional buckling is one of the most important buckling modes of the steel-concrete composite girder under negative moment. In this study, the equivalent lateral and torsional restraints of the bottom flange of a steel-concrete composite girder under negative moments due to variable axial forces are thoroughly investigated. The results show that there is a coupling effect between the applied forces and the lateral and torsional restraint of the bottom flange. Based on the calculation formula of lateral and torsional restraints, the critical buckling stress of I-steel-concrete composite girders and steel-concrete composite box girders under variable axial force is obtained. The critical bending moment of the steel-concrete composite girders can be further calculated. Compared to the traditional calculation methods of elastic foundation beam, the paper introduces an improved method, which considers coupling effect of the external loads and the foundation spring constraints of the bottom flange. Fifteen examples of the steelconcrete composite girders in different conditions are calculated. The calculation results show a good match between the hand calculation and the ANSYS finite element method, which validated that the analytic calculation method proposed in this paper is practical.
\end{abstract}

\section{Introduction}

The steel-concrete composite girders are a type of important lateral-load-carrying composite element. A concrete floor or concrete deck and a steel girder are combined by shear connections and hence the steel girder and concrete slab carry loads together. The existence of the concrete slab can improve the entire and local stability. The steel-concrete composite girder has light self-weight, strong lateral restraint, good fire resistance, and durability. In terms of strength, ductility, and stability, this type of component is of high compressive stress resistance benefitting from the concrete and excellent tensile resistance because of the steel. Besides, this steel-concrete composite girder is an ecofriendly structure. With effective steel recycling and high construction speed, steel-concrete composite girders have shown promising potential in the future construction market [1-4].
The negative bending moment area of the steel girder in a steel-concrete composite girder will be subjected to the constraint caused by the concrete slab and, hence, experience buckling. Chen and Jia [5] studied the ultimate resistance of a continuous composite beam, and the investigations indicated that the ultimate resistance was governed by either distortional lateral buckling or local buckling or an interactive mode of the two. Svensson [6] improved the method of elastic foundation beam under constant axial force, which was based on the assumption that the concrete slab was totally rigid. The method also introduced variable axial elastic foundation struts so as to consider the bending gradient effect. However, Williams and Jemah [7] found that Svensson's method is not safe enough and suggested increasing the involved area of the web. Goltermann and Svensson [8] further developed Williams' models, by solving the eigenvalue of a four-step 
differential equation to understand the buckling of steelconcrete composite girders in the negative moment area caused by variable axial force. In 1982, Swedish code for light-gauge metal structures first simplified the issue [9], by deeming the buckling analysis of steel-concrete composite girder in negative moment area as a stability study of the elastic foundation beam under constant axial force, that is, the method of elastic foundation beam under constant axial force. British Bridge Standard (BS5400) [10] also employs this method to the design of continuous composite girders. British Steel Structure Institute [11] obtained a calculation formula of the critical stress $M_{\mathrm{cr}}$ in the buckling analysis of steel-concrete composite girders in negative moment area by using energy method. Jiang et al. [12] presented a stability analysis calculation model of composite box beam considering rotation of steel beam top flange and established the critical bending moment calculation formula of distortional buckling by employing energy method. Due to the limited computation capacity at that time, the articles reviewed above did not carry on a detailed analysis on the applicability of the elastic foundation beam method. It requires further investigation especially on whether the variable axial strut is equivalent to the steel-concrete composite girder when considering the real bending gradient. Based on Svensson's elastic foundation strut model, Ye et al. [13, 14] made an improvement on the lateral and torsional restraints of the elastic foundation strut by considering the involved part of the web and pointed out that the elastic foundation beam method was more reasonable than the energy method. The buckling analysis of a multispan steel-concrete composite girder via a three-step simplification can be carried out. However, this method cannot be applied to composite girders under complex loads. Zhou et al. $[15,16]$ undertook a research on the equivalent lateral and torsional restraints of the bottom flanges in negative moment areas of I-steel-concrete girders and steel-concrete composite box girders. Corresponding calculation formulae were proposed, and the results indicated a coupling relation between the external loads and the torsional and lateral restraints of the bottom flange.

In this paper, the calculation formulae of the lateral and torsional restraints under variable axial force are proposed by considering the coupling effect of restraint and external loads. The critical buckling stress and critical bending moment of the steel-concrete composite girder are further developed. Finally, the precision analysis of the proposed formula is conducted with an example. The calculation method provides a theoretical basis for further studying of the ultimate resistance of the steel-concrete composite girder under variable axial force.

\section{Basic Assumptions}

The cross-section dimensions of a steel-concrete composite girder are shown in Figure 1. The distortional buckling mode of the steel girder in a composite girder is different from that of an unconstraint steel girder. The top flange of the steel girder in the composite girder is inserted into the concrete slab, which has greater lateral and torsional restraint

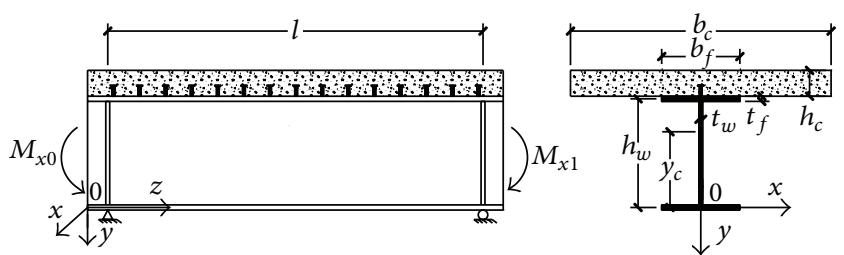

Figure 1: Cross-section dimensions of steel-concrete composite girders and axes.

stiffness. Therefore, both lateral deformation and torsional deformation of the steel girder are restrained by the concrete slab. The lateral buckling of the composite girder happens with the torsional bucking of the lateral distortion of the steel web, as shown in Figure 2. To simplify calculation, the following assumptions are made.

(1) The lateral bending stiffness and torsional stiffness of the concrete slab are relatively greater. The top flange of the steel girder is restricted by the concrete slab so that the lateral distortion and torsional distortion cannot take place.

(2) Tensile resistance of the concrete slab is ignored.

(3) Since no vertical deformation corresponding to flexural buckling occurs when the distortional buckling happens [5-8, 13-17], the vertical restraint stiffness of the bottom flange is deemed to be infinity; that is, $k_{y}=\infty$.

\section{Restraining Stiffness Analysis of the Web of Steel-Concrete Composite Girder}

According to the above assumptions, the compression stress at the edge of the bottom flange by considering the reinforcement within the flanges of concrete slabs under negative bending moment is expressed as

$$
\sigma_{1}(\xi)=\frac{M_{x}(\xi) y_{c}}{I},
$$

where $\xi=z / l$ is a normalization parameter, $0 \leq \xi \leq 1, l$ is the length of the composite girder, $M_{x}(z)$ is the negative bending moment acting on the composite girder, and $-y_{c}$ is the center position of the equivalent cross-section in the vertical axis and can be expressed by (3).

The varying compression stress in order to take into account the moment gradient is expressed as

$$
\sigma_{1}(\xi)=\sigma_{0}\left(a_{0}+a_{1} \xi+a_{2} \xi^{2}\right)
$$

where $\sigma_{0}$ is the maximum compression stress of the bottom flange. Here, by definition, positive $\sigma_{1}$ denotes compression stress and coefficients $a_{0}, a_{1}$, and $a_{2}$ represent different load conditions: (1) $a_{0}=1, a_{1}=0$, and $a_{2}=0$ stand for the pure bending moment; (2) $a_{0}=0, a_{1}=1$, and $a_{2}=0$ represent triangle negative bending moment; (3) $a_{0}=0, a_{1}=4$, and $a_{2}=-4$ are uniform distributed loads. 


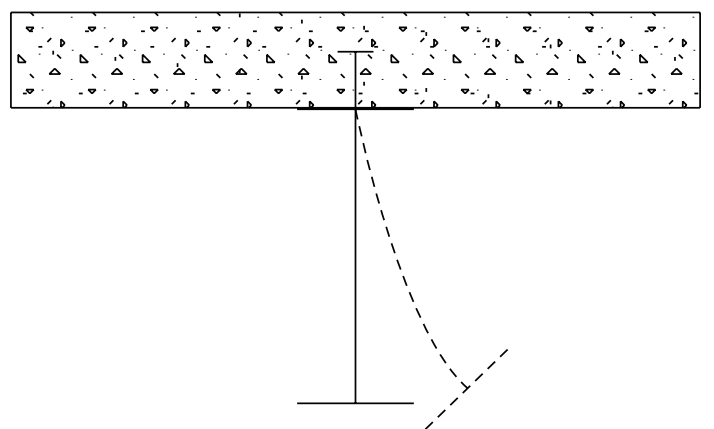

- Original shape

- - - Shape after deformation

FIGURE 2: Distortional buckling of steel-concrete composite girders under negative moments.

Consider

$$
y_{c}=\frac{A_{s} y_{s}+A_{t} h_{w}+0.5 A_{w} h_{w}}{A_{s}+A_{t}+A_{w}+A_{f}}
$$

where $A_{f}$ is the area of the bottom flange, $A_{t}$ is the area of the top flange, $A_{w}$ is the area of the steel web, $A_{s}$ is the area of reinforcements within concrete slab, and $y_{s}$ is the distance of the center position of the equivalent cross-section to the edge of steel flange.

3.1. The Torsional Restraint of the Steel Web. The simplified model of the steel web is shown as in Figure 3. Two transverse edges are simply supported. The junction of the web and top flange is fixed while the junction of web and bottom flange is simply supported. The boundary condition of the buckling of the steel web is $[15,16]$ given as follows:

$$
\begin{gathered}
{[w]_{z=0, l}=0, \quad[w]_{y=0,-h_{w}}=0, \quad\left[w_{, y}\right]_{y=-h_{w}}=0,} \\
{\left[-D_{w}\left(w_{, z z}+\mu w_{, y y}\right)\right]_{z=0, l}=0,}
\end{gathered}
$$

where $D_{w}=E t_{w}^{3} / 12\left(1-\mu^{2}\right), \mu$ is Poisson's ratio of steel, $E$ is the elasticity modulus of steel, $w(y, z)$ is the buckling deformation function of web, $t_{w}$ is the thickness of the steel girder web, and $h_{w}$ is the height of the steel girder web.

Based on the boundary conditions, the buckling deformation function of the steel web is

$$
w=\left[\frac{y}{h_{w}}+2\left(\frac{y}{h_{w}}\right)^{2}+\left(\frac{y}{h_{w}}\right)^{3}\right]\left(\sum_{i=1}^{n} c_{i} \sin \frac{i \pi z}{l}\right) .
$$

According to the principle of stationary potential energy [18-20], the buckling characteristic equation is given as follows:

$$
\left(\mathbf{B}_{0}+k_{\varphi 1} \mathbf{T}-\sigma_{0} \mathbf{N}_{0}\right) \mathbf{C}=0,
$$

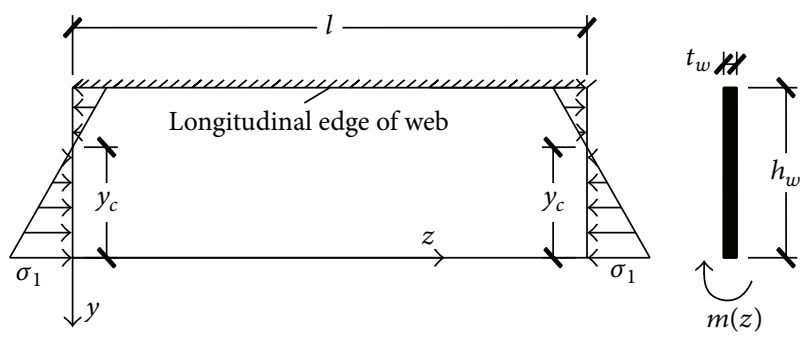

FIGURE 3: Rectangular plate under compression and moments.

where $B_{0 i i}=l D_{w}\left(\left(2 / h_{w}^{3}\right)+\left(h_{w} i^{4} \beta^{2} / 210\right)+\left(2 i^{2} \beta / 15 h_{w}\right)\right), T_{i i}=$ $l / 2 h_{w}^{2}, B_{0 i j}=T_{i j}=0(i \neq j), N_{0 i i}=\left(\pi^{2} g_{i} / l\right)\left(\left(t_{w} h_{w} / 210\right)-\right.$ $\left.\left(t_{w} h_{w}^{2} / 560 y_{c}\right)\right), \beta=\pi^{2} / l^{2}, N_{0 i j}=\left(t_{w} h_{w} b_{i j} / l\right)\left((1 / 105)-\left(h_{w} /\right.\right.$ $\left.\left.280 y_{c}\right)\right)(i \neq j), b_{i j}=\left\{\left[(-1)^{i+j}-1\right] a_{1}+2(-1)^{i+j} a_{2}\right\}\left(i j\left(i^{2}+\right.\right.$ $\left.\left.j^{2}\right) /\left(i^{2}-j^{2}\right)^{2}\right), g_{i}=i^{2}\left[a_{0}+\left(a_{1} / 2\right)+a_{2}\left((1 / 3)+\left(1 / 2 i^{2} \pi^{2}\right)\right)\right], k_{\varphi 1}$ is the lateral restraint stiffness of the web by the bottom flange, and $\mathbf{C}=\left\{c_{1}, c_{2}, \ldots, c_{n}\right\}^{T}$ is general coordinates and represents the buckling distortion.

According to the elastic plate theory, the lateral distribution force of the web is given as follows [21]:

$$
\begin{aligned}
f_{x \varphi}= & -D_{w}\left[\frac{\partial^{3} w}{\partial y^{3}}+(2-\mu) \frac{\partial^{3} w}{\partial z^{2} \partial y}\right], \\
\left.f_{x \varphi}\right|_{y=0}= & -\frac{6 D_{w}}{h_{w}^{3}}\left(\sum_{i=1}^{n} c_{i} \sin \frac{i \pi z}{l}\right) \\
& +D_{w} \beta \frac{(2-\mu)}{h_{w}}\left(\sum_{i=1}^{n} c_{i} i^{2} \sin \frac{i \pi z}{l}\right) .
\end{aligned}
$$

3.2. The Lateral Restraint of the Steel Web. The simplified model of the steel web is shown as in Figure 4. Two transverse edges are simply supported, and the junction of the web and top flange is fixed. The junction of web and bottom flange is free in the transverse direction. The boundary condition of the buckling of the steel web is $[15,16]$ given as follows:

$$
\begin{gathered}
{[w]_{z=0, l}=0, \quad[w]_{y=-h_{w}}=0, \quad\left[w_{, y}\right]_{y=0,-h_{w}}=0,} \\
{\left[-D_{w}\left(w_{, z z}+\mu w_{, y y}\right)\right]_{z=0, l}=0 .}
\end{gathered}
$$

According to the boundary condition, the buckling deformation function of the steel web can be expressed as

$$
w=\left[1-3\left(\frac{y}{h_{w}}\right)^{2}-2\left(\frac{y}{h_{w}}\right)^{3}\right]\left(\sum_{i=1}^{n} d_{i} \sin \frac{i \pi z}{l}\right) .
$$

According to the principle of stationary potential energy $[18,20]$, the buckling characteristic equation is given as follows:

$$
\left(\mathbf{H}_{0}+k_{x 1} \mathbf{R}-\sigma_{0} \mathbf{S}_{0}\right) \mathbf{D}=0,
$$




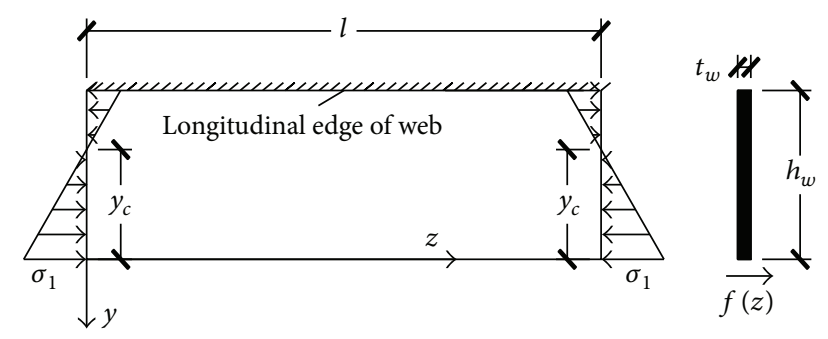

FIgURE 4: Rectangular plate under compression and lateral stress.

where $R_{i j}=H_{0 i j}=0(i \neq j), R_{i i}=l / 2, H_{0 i i}=l D_{w}\left(\left(6 / h_{w}^{3}\right)+\right.$ $\left.\left(13 h_{w} / 70\right) \beta^{2} i^{4}+\left(6 / 5 h_{w}\right) \beta i^{2}\right), S_{0 i j}=\left(t_{w} h_{w} b_{i j} / l\right)((13 / 35)-$ $\left.\left(3 h_{w} / 35 y_{c}\right)\right)(i \neq j), S_{0 i i}=\left(t_{w} h_{w} \pi^{2} g_{i} / l\right)\left((13 / 70)-\left(3 h_{w} /\right.\right.$ $\left.\left.70 y_{c}\right)\right), k_{x 1}$ is the lateral restraint stiffness of the web by the bottom flange, and $\mathbf{D}=\left\{d_{1}, d_{2}, \ldots, d_{n}\right\}^{T}$ is general coordinates and represents the buckling distortion of the bottom flange.

According to the elastic plate theory, the lateral distributed bending moment of the web is [21] given as follows:

$$
\begin{aligned}
f_{\varphi x}= & -D_{w}\left(\frac{\partial^{2} w}{\partial y^{2}}+\mu \frac{\partial^{2} w}{\partial z^{2}}\right), \\
\left.f_{\varphi x}\right|_{y=0}= & D_{w} \frac{6}{h_{w}^{2}}\left(\sum_{i=1}^{n} d_{i} \sin \frac{i \pi z}{l}\right) \\
& +D_{w} \mu \beta\left(\sum_{i=1}^{n} d_{i} i^{2} \sin \frac{i \pi z}{l}\right) .
\end{aligned}
$$

3.3. Restraint Analysis of the Steel Web. $k_{\varphi 1}$ and $k_{x 1}$ can be determined by the following equations:

$$
\begin{aligned}
& \left|\mathbf{B}+k_{\varphi 1} \mathbf{T}-\sigma_{0} \mathbf{N}\right|=0, \\
& \left|\mathbf{H}+k_{x 1} \mathbf{R}-\sigma_{0} \mathbf{S}\right|=0 .
\end{aligned}
$$

It can be found from (12) that there is a coupling relation between external loads and torsional/lateral restraint stiffness. It indicates that both the torsional and lateral restraints of the bottom flange are not only determined by the cross-section features of the composite girder, but they also depended on the external loads. Therefore, it may not be appropriate to take the restraint stiffness as a constant material feature in the traditional elastic foundation beam method.

\section{Buckling Analysis of I-Steel-Concrete Composite Girders}

According to the assumptions made upon, the buckling model of the I-steel-composite girder can be simplified as the model depicted in Figure 5. The horizontal and torsional directions of the thin plate are restricted by springs while the vertical direction is rigidly restricted.

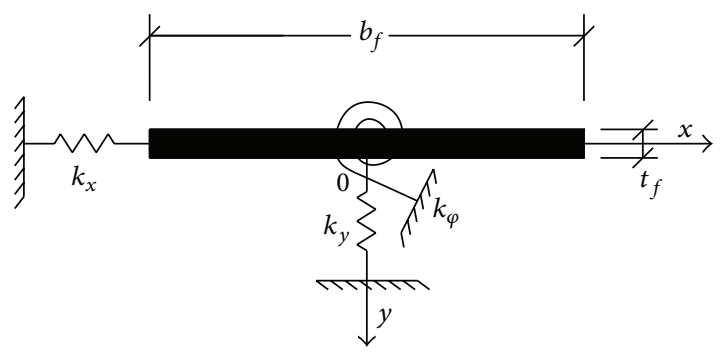

FIGURE 5: Simplified calculation model of steel-concrete composite girders.

In Figure 5, the thin plate is symmetric about both $x$-axis and $y$-axis. The centroid of the plate is set to be the origin point. Assuming the horizontal lateral displacement of the bottom flange is $u(z)$ and the torsional angle is $\varphi(z)$, the neutral equilibrium differential equation of an elastic thinwalled bar under variable axial force can be expressed as [17]

$$
\begin{gathered}
E I_{y} u^{I V}+\left[P\left(u^{\prime}+y_{a} \varphi^{\prime}\right)\right]^{\prime}+k_{x}\left[u-\left(y_{d}-y_{a}\right) \varphi\right] \\
-f_{x \varphi}=0, \\
E I_{x} v^{I V}+\left[P\left(v^{\prime}-x_{a} \varphi^{\prime}\right)\right]^{\prime}+k_{y}\left[v+\left(x_{d}-x_{a}\right) \varphi\right]=0, \\
E I_{w} \varphi^{I V}+\left[\left(P r_{0}^{2}-G J\right) \varphi^{\prime}\right]^{\prime}-k_{x}\left[u-\left(y_{d}-y_{a}\right) \varphi\right] \\
\times\left(y_{d}-y_{a}\right)+f_{\varphi x}-x_{a}\left(P v^{\prime}\right)^{\prime}+y_{a}\left(P u^{\prime}\right)^{\prime} \\
+k_{y}\left[v+\left(x_{d}-x_{a}\right) \varphi\right]\left(x_{d}-x_{a}\right)+k_{\varphi} \varphi=0,
\end{gathered}
$$

where $I_{y}=t_{f} b_{f}^{3} / 12, I_{x}=b_{f} t_{f}^{3} / 12, J=b_{f} t_{f}^{3} / 3, r_{0}^{2}=x_{a}^{2}+$ $y_{a}^{2}+\left(I_{x}+I_{y}\right) / A_{s}$, and $x_{a}$ is center position of the curved bottom flange in the horizontal axis; here, $x_{a}=0 . y_{a}$ is the center position of the curved bottom flange in the vertical axis; here, $y_{a}=0 . x_{d}$ is the rotation axis of the bottom flange in the horizontal axis; here, $x_{d}=0 . y_{d}$ is the rotation axis of the bottom flange in the vertical axis; here, $y_{d}=0 . I_{w}$ is the sectorial inertia moment of bottom flange; here, $I_{w}=0 . G$ is shear modulus of the steel, $P$ is the pressure of the bottom flange, $P=A_{f} \sigma_{0}\left(a_{0}+a_{1} \xi+a_{2} \xi^{2}\right), k_{\varphi}=-k_{\varphi 1}$, and $k_{x}=-k_{x 1}$.

Plugging $y_{a}=0, y_{d}=0, x_{a}=0, x_{d}=0, v=0$, and $I_{w}=$ 0 into (13) leads to

$$
\begin{gathered}
\left(P r_{0}^{2}-G J\right) \varphi^{\prime \prime}+r_{0}^{2} P^{\prime} \varphi^{\prime}+k_{\varphi} \varphi+f_{\varphi x}=0, \\
E I_{y} u^{I V}+P^{\prime} u^{\prime}+P u^{\prime \prime}+k_{x} u-f_{x \varphi}=0 .
\end{gathered}
$$

By combining (5) and (9), the torsional angle and lateral displacement of the bottom flange of the composite girder can be obtained:

$$
\begin{gathered}
\varphi(z)=\sum_{i=1}^{n} \frac{c_{i}}{h_{w}} \sin \frac{i \pi z}{l}, \\
u(z)=\sum_{i=1}^{n} d_{i} \sin \frac{i \pi z}{l} .
\end{gathered}
$$


According to the Galerkin method $[15,22]$, we have

$$
\left(\begin{array}{cc}
\mathbf{B}_{1}+k_{\varphi} \mathbf{T}-\sigma_{0} \mathbf{N}_{1} & \mathbf{Q} \\
\mathbf{M} & \mathbf{H}_{1}+k_{x} \mathbf{R}-\sigma_{0} \mathbf{S}_{1}
\end{array}\right)\left(\begin{array}{l}
\mathbf{C} \\
\mathbf{D}
\end{array}\right)=0
$$

where $B_{1 i j}=Q_{i j}=H_{1 i j}=M_{i j}=0(i \neq j), B_{1 i i}=$ $G J\left(i^{2} \pi^{2} / 2 l h_{w}^{2}\right), M_{i i}=\left(3 D_{w} l / h_{w}^{3}\right)-D_{w}\left((2-\mu) i^{2} l \beta / 2 h_{w}\right), Q_{i i}=$ $3\left(D_{w} l / h_{w}^{3}\right)+\left(D_{w} \mu l \beta i^{2} / 2 h_{w}\right), N_{1 i i}=\left(A_{f} r_{0}^{2} \pi^{2} g_{i} / 2 l h_{w}^{2}\right), N_{1 i j}=$ $\left(A_{f} r_{0}^{2} b_{i j} / l h_{w}^{2}\right)(i \neq j), H_{1 i i}=E I_{y} \beta^{2}\left(i^{4} l / 2\right), S_{1 i i}=\left(A_{f} \pi^{2} g_{i} /\right.$ $2 l)$, and $S_{1 i j}=\left(A_{f} b_{i j} / l\right)(i \neq j)$.

The combination of (6), (10), and (16) leads to

$$
\left[\left(\begin{array}{cc}
\mathbf{B} & \mathbf{Q} \\
\mathbf{M} & \mathbf{H}
\end{array}\right)-\sigma_{0}\left(\begin{array}{cc}
\mathbf{N} & \mathbf{0} \\
\mathbf{0} & \mathbf{S}
\end{array}\right)\right]\left(\begin{array}{l}
\mathbf{C} \\
\mathbf{D}
\end{array}\right)=0
$$

where $\mathbf{B}=\mathbf{B}_{0}+\mathbf{B}_{1}, \mathbf{N}=\mathbf{N}_{0}+\mathbf{N}_{1}, \mathbf{H}=\mathbf{H}_{0}+\mathbf{H}_{1}$, and $\mathbf{S}=$ $\mathbf{S}_{0}+\mathbf{S}_{1}$.

The deformation vector $\left\{\mathbf{C}^{T}, \mathbf{D}^{T}\right\}^{T}$ cannot be zero when buckling happens. Therefore, the buckling of the composite girder can be solved by the generalized eigenvalue of the characteristic matrix shown as follows:

$$
\left|\left(\begin{array}{cc}
\mathbf{B} & \mathbf{Q} \\
\mathbf{M} & \mathbf{H}
\end{array}\right)-\sigma_{0}\left(\begin{array}{cc}
\mathbf{N} & \mathbf{0} \\
\mathbf{0} & \mathbf{S}
\end{array}\right)\right|=0
$$

By solving (18), $2 n$ generalized eigenvalue can be obtained: $\sigma_{t i}(i=1,2, \ldots, 2 n)$; let $\sigma_{\mathrm{cr}}=\min \left\{\sigma_{t i}(i=\right.$ $1,2, \ldots, 2 n)\} ; \sigma_{\mathrm{cr}}$ is the critical buckling stress of the composite girder. The critical buckling moment of composite girder can be calculated by the following equation:

$$
M_{\mathrm{cr}}=\frac{\sigma_{\mathrm{cr}}\left(a_{0}+a_{1} \xi+a_{2} \xi^{2}\right) I}{y_{c}} .
$$

\section{Buckling Analysis of the Steel-Concrete Composite Box Girder}

The dimensions of the composite box girder are shown in Figure 6. According to the assumptions made above, the buckling model of the composite box girder can be simplified as a thin-plate model that is restricted by springs in horizontal and torsional directions, rigidly restricted in vertical direction. The simplified model is shown in Figure 7.

As the derivation in Section 3, the following can be obtained:

$$
\begin{gathered}
\left(\mathbf{B}_{0}+k_{\varphi_{l} 1} \mathbf{T}-\sigma_{0} \mathbf{N}_{0}\right) \mathbf{C}_{l}=0 \\
\left(\mathbf{B}_{0}+k_{\varphi_{r} 1} \mathbf{T}-\sigma_{0} \mathbf{N}_{0}\right) \mathbf{C}_{r}=0 \\
\left(\mathbf{H}_{0}+k_{x 1} \mathbf{R}-\sigma_{0} \mathbf{S}_{0}\right) \mathbf{D}=0
\end{gathered}
$$

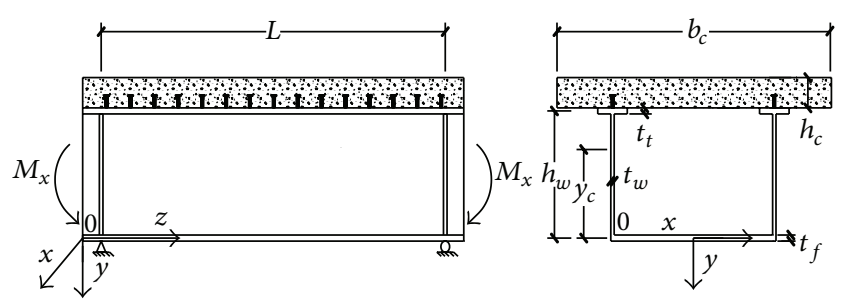

Figure 6: Cross-section dimensions of steel-concrete composite box girder.

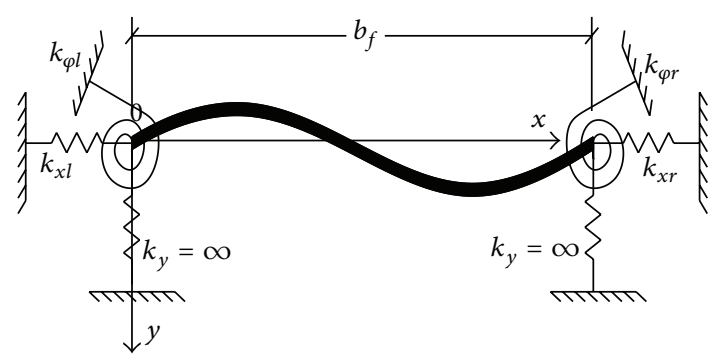

FIGURE 7: Simplified calculation model of steel-concrete composite girders.

$$
\begin{aligned}
\left.f_{x \varphi_{l} \mid}\right|_{y=0}= & -\frac{6 D_{w}}{h_{w}^{3}}\left(\sum_{i=1}^{n} c_{l i} \sin \frac{i \pi z}{L}\right) \\
& +D_{w} \beta \frac{(2-\mu)}{h_{w}}\left(\sum_{i=1}^{n} c_{l i} i^{2} \sin \frac{i \pi z}{L}\right), \\
f_{\left.x \varphi_{r}\right|_{y=0}=} & -\frac{6 D_{w}}{h_{w}^{3}}\left(\sum_{i=1}^{n} c_{r i} \sin \frac{i \pi z}{l}\right) \\
& +D_{w} \beta \frac{(2-\mu)}{h_{w}}\left(\sum_{i=1}^{n} c_{r i} i^{2} \sin \frac{i \pi z}{l}\right), \\
\left.f_{\varphi x}\right|_{y=0}= & \frac{6 D_{w}}{h_{w}^{2}}\left(\sum_{i=1}^{n} d_{i} \sin \frac{i \pi z}{l}\right) \\
& +D_{w} \mu \beta\left(\sum_{i=1}^{n} d_{i} i^{2} \sin \frac{i \pi z}{l}\right),
\end{aligned}
$$

where $k_{\varphi_{1} 1}$ is the torsional restraint stiffness of left web by the bottom flange, $\mathbf{C}_{l}=\left\{c_{l 1}, c_{l 2}, \ldots, c_{l n}\right\}^{T}$ is buckling general coordinates of the left web, $k_{\varphi_{r} 1}$ is torsional restraint stiffness of the right web by the bottom flange, $\mathbf{C}_{r}=\left\{c_{r 1}, c_{r 2}, \ldots, c_{r n}\right\}^{T}$ is buckling general coordinates of the right web, $k_{x 1}$ is lateral restraint stiffness of the steel web by the bottom flange, and $\mathbf{D}=\left\{d_{1}, d_{2}, \ldots, d_{n}\right\}^{T}$ is buckling general coordinates of the bottom flange.

As Figure 7 shows, the lateral displacement buckling function of the horizontal buckling of the bottom flange is $u(z)$, the out-plane buckling deformation function of the 
bottom flange is $v(x, z)$, the left rotational angle is $\varphi_{l}(z)$, and the right rotational angle is $\varphi_{r}(z)$. The boundary condition of the bottom flange is given as follows:

$$
\begin{array}{cc}
\left.v\right|_{x=0}=0, & \left.v_{, x}\right|_{x=0}=\varphi_{l}(z), \\
\left.v\right|_{x=b_{f}}=0, & \left.v_{, x}\right|_{x=b_{f}}=\varphi_{r}(z) .
\end{array}
$$

According to compatibility of deformation, the displacement function of the bottom flange is

$$
v=\frac{b_{f}}{2 \pi} \sin \frac{\pi x}{b_{f}}\left(\varphi_{l}-\varphi_{r}\right)+\frac{b_{f}}{4 \pi} \sin \frac{2 \pi x}{b_{f}}\left(\varphi_{l}+\varphi_{r}\right) .
$$

According to the principle of stationary potential energy, the buckling characteristic equations are given as follows:

$$
\begin{gathered}
D_{f}\left(\frac{5 \pi^{2} \varphi_{l}}{8 b_{f}}+\frac{3 \pi^{2} \varphi_{r}}{8 b_{f}}-\frac{b_{f} \varphi_{l}^{\prime \prime}}{2}+\frac{5 b_{f}^{3} \varphi_{l}^{\prime \prime \prime \prime}}{32 \pi^{2}}-\frac{3 b_{f}^{3} \varphi_{r}^{\prime \prime \prime \prime}}{32 \pi^{2}}\right) \\
+\left(\frac{5 \sigma A_{f} b_{f}^{2} \varphi_{l}^{\prime}}{32 \pi^{2}}\right)^{\prime}-\left(\frac{3 \sigma A_{f} b_{f}^{2} \varphi_{r}^{\prime}}{32 \pi^{2}}\right)^{\prime}+k_{\varphi_{l}} \varphi_{l}+f_{\varphi x}=0 \\
2 k_{x} u+\left(\sigma A_{f} u^{\prime}\right)^{\prime}+E I_{y} u^{\prime \prime \prime \prime}-f_{x \varphi_{l}}-f_{x \varphi_{r}}=0 \\
D_{f}\left(\frac{5 \pi^{2} \varphi_{r}}{8 b_{f}}+\frac{3 \pi^{2} \varphi_{l}}{8 b_{f}}-\frac{b_{f} \varphi_{r}^{\prime \prime}}{2}+\frac{5 b_{f}^{3} \varphi_{r}^{\prime \prime \prime \prime}}{32 \pi^{2}}-\frac{3 b_{f}^{3} \varphi_{l}^{\prime \prime \prime \prime}}{32 \pi^{2}}\right) \\
+\left(\frac{5 \sigma A_{f} b_{f}^{2} \varphi_{r}^{\prime}}{32 \pi^{2}}\right)^{\prime}-\left(\frac{3 \sigma A_{f} b_{f}^{2} \varphi_{l}^{\prime}}{32 \pi^{2}}\right)^{\prime}+k_{\varphi_{r}} \varphi_{j}+f_{\varphi x}=0
\end{gathered}
$$

where $I_{y}=t_{f} b_{f}^{3} / 12, t_{f}$ is the thickness of bottom flange, $b_{f}$ is the width of the bottom flange, $D_{f}=E t_{f}^{3} / 12\left(1-\mu^{2}\right), k_{\varphi_{l}}=$ $-k_{\varphi_{1} 1}$ is torsional restraint stiffness of the bottom flange edge by the left steel web, $k_{\varphi_{r}}=-k_{\varphi_{r} 1}$ is torsional restraint stiffness of the bottom flange edge by the right steel web, and $k_{x}=-k_{x 1}$ is lateral restraint stiffness of the bottom flange edge by the steel web.

According to the Galerkin method $[15,16]$, we have

$$
\begin{aligned}
& \left(\begin{array}{ccc}
\mathbf{B}_{1}+k_{\varphi_{l}} \mathbf{T}-\sigma_{0} \mathbf{N}_{1} & \mathbf{F}+0.6 \sigma_{0} \mathbf{N}_{1} & \mathbf{Q} \\
\mathbf{F}+0.6 \sigma_{0} \mathbf{N}_{1} & \mathbf{B}_{1}+k_{\varphi_{r}} \mathbf{T}-\sigma_{0} \mathbf{N}_{1} & \mathbf{Q} \\
\mathbf{M} & \mathbf{M} & \mathbf{H}_{1}-\sigma_{0} \mathbf{S}_{1}+2 k_{x} \mathbf{R}
\end{array}\right) \\
& \times \boldsymbol{\eta}=0,
\end{aligned}
$$

\begin{tabular}{|c|c|c|c|c|c|c|}
\hline $\begin{array}{l}\text { Example } \\
\text { number }\end{array}$ & $\begin{array}{l}\text { Cross- } \\
\text { section } \\
\text { number }\end{array}$ & $h_{w} / \mathrm{mm}$ & $b_{f} / \mathrm{mm}$ & $t_{f} / \mathrm{mm}$ & $t_{w} / \mathrm{mm}$ & $l / \mathrm{mm}$ \\
\hline 1 & & & & & & 4500 \\
\hline 2 & 1 & 600 & 200 & 12 & 12 & 7200 \\
\hline 3 & & & & & & 9600 \\
\hline 4 & & & & & & 3000 \\
\hline 5 & 2 & 600 & 120 & 10 & 10 & 5400 \\
\hline 6 & & & & & & 8400 \\
\hline 7 & & & & & & 6000 \\
\hline 8 & 3 & 719 & 268 & 25 & 16 & 10200 \\
\hline 9 & & & & & & 14400 \\
\hline 10 & & & & & & 3000 \\
\hline 11 & 4 & 300 & 100 & 3 & 3 & 5400 \\
\hline 12 & & & & & & 8400 \\
\hline 13 & & & & & & 4200 \\
\hline 14 & 5 & 450 & 150 & 4 & 4 & 7200 \\
\hline 15 & & & & & & 10200 \\
\hline
\end{tabular}

where $B_{1 i j}=F_{i j}=Q_{i j}=M_{i j}=H_{1 i j}=0(i \neq j), B_{1 i i}=$ $\left(5 D_{f} \pi^{2} l / 16 b_{f} h_{w}^{2}\right)+\left(D_{f} b_{f} \beta l i^{2} / 4 h_{w}^{2}\right)+\left(5 D_{f} b_{f}^{3} \beta^{2} l i^{4} / 64 \pi^{2} h_{w}^{2}\right)$, $F_{i i}=\left(3 D_{f} \pi^{2} l / 16 b_{f} h_{w}^{2}\right)-\left(3 D_{f} b_{f}^{3} \beta^{2} l i^{4} / 64 \pi^{2} h_{w}^{2}\right), Q_{i i}=$ $3\left(D_{w} l / h_{w}^{3}\right)+\left(l D_{w} \mu \beta / 2 h_{w}\right) i^{2}, N_{1 i j}=\left(5 A_{f} b_{f}^{2} b_{i j} / 32 \pi^{2} h_{w}^{2} l\right)(i \neq$ j), $N_{1 i i}=\left(5 A_{f} b_{f}^{2} g_{i} / 64 h_{w}^{2} l\right), M_{i i}=\left(3 D_{w} l / h_{w}^{3}\right)-D_{w}((2-$ $\left.\mu) i^{2} l \beta / 2 h_{w}\right), H_{1 i i}=\left(i^{4} E I_{y} \beta^{2} l / 2\right), S_{1 i i}=\left(A_{f} \pi^{2} g_{i} / 2 l\right), S_{1 i j}=$ $\left(A_{f} b_{i j} / l\right)(i \neq j)$, and $\boldsymbol{\eta}=\left(\mathbf{C}_{l}^{T}, \mathbf{C}_{r}^{T}, \mathbf{D}^{T}\right)^{T}$.
TABLE 1: Basic geometric size of I-steel composite girder cases.

Since the constraint in the theoretical model is higher than the real scenario, the critical buckling stress is increased. Therefore, the theoretical buckling deformation functions of the web and bottom flange cannot accurately describe the real buckling deformation curves. In order to eliminate errors, the paper gives a reduction factor on the torsional restraint stiffness of the bottom flange and the reduction factor is found to be 0.5. Combining (20), (21), (22), and (29) leads to

$$
\left[\left(\begin{array}{ccc}
\mathbf{B} & \mathbf{F} & \mathbf{Q} \\
\mathbf{F} & \mathbf{B} & \mathbf{Q} \\
\mathbf{M} & \mathbf{M} & \mathbf{H}
\end{array}\right)-\sigma_{0}\left(\begin{array}{ccc}
\mathbf{N} & \frac{-3 \mathbf{N}_{1}}{5} & \mathbf{0} \\
\frac{-3 \mathbf{N}_{1}}{5} & \mathbf{N} & \mathbf{0} \\
\mathbf{0} & \mathbf{0} & \mathbf{S}
\end{array}\right)\right] \boldsymbol{\eta}=0
$$

where $\mathbf{B}=\mathbf{B}_{0} / 2+\mathbf{B}_{1}, \mathbf{N}=\mathbf{N}_{0} / 2+\mathbf{N}_{1}, \mathbf{H}=\mathbf{2} \mathbf{H}_{0}+$ $\mathbf{H}_{1}$, and $\mathbf{S}=\mathbf{2} \mathbf{S}_{0}+\mathbf{S}_{1}$.

The deformation vector $\boldsymbol{\eta}$ cannot be zero when the buckling of the composite girder happens. Therefore, the buckling of the composite girder can be solved by the generalized eigenvalue of the characteristic matrix shown as follows:

$$
\left|\left(\begin{array}{ccc}
\mathbf{B} & \mathbf{F} & \mathbf{Q} \\
\mathbf{F} & \mathbf{B} & \mathbf{Q} \\
\mathbf{M} & \mathbf{M} & \mathbf{H}
\end{array}\right)-\sigma_{0}\left(\begin{array}{ccc}
\mathbf{N} & -0.6 \mathbf{N}_{1} & \mathbf{0} \\
-0.6 \mathbf{N}_{1} & \mathbf{N} & \mathbf{0} \\
\mathbf{0} & \mathbf{0} & \mathbf{S}
\end{array}\right)\right|=0 .
$$

$3 n$ general eigenvalues can be obtained from (31), which are $\sigma_{t i}(i=1,2, \ldots, 3 n)$; let $\sigma_{\mathrm{cr}}=\min \left\{\sigma_{t i}(i=\right.$ $1,2, \ldots, 3 n)\} ; \sigma_{\text {cr }}$ is the critical buckling stress of the composite girder. The following equation can calculate the critical buckling moment

$$
M_{\mathrm{cr}}=\frac{\sigma_{\mathrm{cr}}\left(a_{0}+a_{1} \xi+a_{2} \xi^{2}\right) I}{y_{c}} .
$$


TABLE 2: Basic geometric size of steel composite box girder cases.

\begin{tabular}{|c|c|c|c|c|c|c|c|}
\hline Example number & $h_{w} / \mathrm{mm}$ & $b_{f} / \mathrm{mm}$ & $b_{t} / \mathrm{mm}$ & $t_{w} / \mathrm{mm}$ & $t_{f} / \mathrm{mm}$ & $t_{t} / \mathrm{mm}$ & $l / \mathrm{mm}$ \\
\hline 1 & & & & & & & 4000 \\
\hline 2 & 400 & 600 & 100 & 10 & 10 & 10 & 8000 \\
\hline 3 & & & & & & & 12000 \\
\hline 4 & & & & & & & 4000 \\
\hline 5 & 400 & 500 & 100 & 10 & 10 & 10 & 8000 \\
\hline 6 & & & & & & & 12000 \\
\hline 7 & & & & & & & 4000 \\
\hline 8 & 300 & 600 & 100 & 10 & 10 & 10 & 8000 \\
\hline 9 & & & & & & & 12000 \\
\hline 10 & & & & & & & 4000 \\
\hline 11 & 400 & 600 & 120 & 10 & 10 & 10 & 8000 \\
\hline 12 & & & & & & & 12000 \\
\hline 13 & & & & & & & 4000 \\
\hline 14 & 400 & 600 & 100 & 12 & 12 & 12 & 8000 \\
\hline 15 & & & & & & & 12000 \\
\hline
\end{tabular}

TABLE 3: Critical distortional buckling moment of I-steel composite girder under negative uniform moment.

\begin{tabular}{lccccc}
\hline \multirow{2}{*}{$\begin{array}{l}\text { Example } \\
\text { number }\end{array}$} & \multicolumn{6}{c}{ Distortional buckling critical moment $M_{\mathrm{cr}} / \mathrm{kN} \cdot \mathrm{m}$} \\
& ANSYS & Williams & Goltermann & Svensson & $(19)$ \\
\hline 1 & 1129.1 & 1060.6 & 1193.6 & 1540.1 & 1138.3 \\
2 & 1212.3 & 1148.0 & 1234.4 & 1664.7 & 1203.9 \\
3 & 1149.7 & 1077.0 & 1197.1 & 1561.7 & 1155.0 \\
\hline 4 & 390.98 & 354.02 & 405.88 & 619.6 & 404.40 \\
5 & 410.19 & 375.12 & 436.86 & 656.6 & 421.61 \\
6 & 401.97 & 366.03 & 469.19 & 640.6 & 414.12 \\
\hline 7 & 3672.7 & 3126.4 & 3521.1 & 3899.1 & 3720.0 \\
8 & 3836.5 & 3390.4 & 4014.3 & 4228.1 & 3874.5 \\
9 & 3905.1 & 3226.8 & 4245.4 & 4024.2 & 3932.7 \\
\hline 10 & 34.155 & 33.710 & 35.235 & 48.9 & 32.632 \\
11 & 35.235 & 34.884 & 36.464 & 50.6 & 33.587 \\
12 & 34.729 & 34.304 & 35.951 & 49.7 & 33.106 \\
\hline 13 & 94.611 & 94.325 & 101.817 & 136.8 & 89.713 \\
14 & 107.307 & 107.811 & 102.911 & 156.3 & 101.31 \\
15 & 91.161 & 90.153 & 93.920 & 130.7 & 86.372 \\
\hline
\end{tabular}

\section{Analysis of Examples}

The geometric dimensions of each example are listed in Tables 1 and 2. By means of the calculation method introduced in this paper and the finite element method, the critical buckling analysis of the composite girder under uniform negative bending moment, triangle bending moment, and uniform loads can be carried out. Svensson's method, Williams' method, and Goltermann's method are also employed in the calculation of various I-steel-concrete composite girders, so as to validate the calculation method proposed in this paper. The finite element analysis is conducted by using ANSYS commercial software. Element SHELL43 is adopted to model
TABLE 4: Critical distortional buckling moment of I-steel composite girder under negative triangular moment.

\begin{tabular}{lccccc}
\hline \multirow{2}{*}{$\begin{array}{l}\text { Example } \\
\text { number }\end{array}$} & \multicolumn{6}{c}{ Distortional buckling critical moment $M_{\text {cr }} / \mathrm{kN} \cdot \mathrm{m}$} \\
& ANSYS & Williams & Goltermann & Svensson & $(19)$ \\
\hline 1 & 1868.6 & 1838.8 & 1971.4 & 2665.4 & 1925.2 \\
2 & 1726.4 & 1680.5 & 1774.0 & 2436.7 & 1735.8 \\
3 & 1590.9 & 1528.8 & 1621.3 & 2216.2 & 1597.4 \\
\hline 4 & 659.9 & 632.7 & 713.2 & 1107.2 & 703.15 \\
5 & 586.6 & 550.6 & 605.6 & 963.3 & 601.56 \\
6 & 525.7 & 484.6 & 535.7 & 848.1 & 538.84 \\
\hline 7 & 6125.2 & 5530.4 & 6144.4 & 6897.2 & 6353.4 \\
8 & 5523.5 & 4945.5 & 5438.7 & 6167.4 & 5607.5 \\
9 & 5060.4 & 4435.0 & 4923.2 & 5531.0 & 5119.1 \\
\hline 10 & 55.183 & 59.346 & 61.236 & 86.0 & 56.167 \\
11 & 51.574 & 51.935 & 53.366 & 75.3 & 49.469 \\
12 & 46.366 & 46.184 & 47.412 & 67.0 & 44.224 \\
\hline 13 & 131.762 & 170.748 & 181.683 & 247.6 & 133.61 \\
14 & 129.117 & 147.906 & 150.336 & 214.4 & 129.98 \\
15 & 127.803 & 131.099 & 134.420 & 190.1 & 124.08 \\
\hline
\end{tabular}

the steel girder. The concrete slab of the composite girder is replaced with constraints in the numerical simulation. The motions in $x$ and $y$ directions of the top flange edge are restrained to represent the lateral and torsional restrictions caused by the concrete slab in practice. The results of each simplified calculation method are listed in Tables 3, 4, 5, and 6 , and the error analyses of each simplified method are shown in Figures 8, 9, 10, and 11 .

The following conclusions can be drawn based on the results presented in Tables 3 to 6 and Figures 8 to 11 .

(1) Under uniform negative bending moment, the critical bending buckling moment in the same crosssection of the composite girder is rarely affected by 
TABLE 5: Critical distortional buckling moment of I-steel composite girder under uniformly distributed load.

\begin{tabular}{lccccc}
\hline $\begin{array}{l}\text { Example } \\
\text { number }\end{array}$ & \multicolumn{5}{c}{ Distortional buckling critical moment $M_{\mathrm{cr}} / \mathrm{kN} \cdot \mathrm{m}$} \\
& ANSYS & Williams & Goltermann & Svensson & $(19)$ \\
\hline 3 & 1551.2 & 1539.4 & 1638.8 & 2232.1 & 1616.0 \\
\hline 6 & 527.2 & 498.8 & 550.8 & 872.9 & 551.10 \\
\hline 9 & 5038.3 & 4509.3 & 5000.1 & 5623.4 & 5235.1 \\
\hline 11 & 49.7 & 52.610 & 54.675 & 76.289 & 50.317 \\
12 & 45.9 & 47.925 & 47.925 & 67.500 & 44.533 \\
\hline 13 & 129.9 & 198.896 & 204.768 & 288.401 & 129.10 \\
14 & 126.7 & 165.281 & 165.645 & 239.639 & 126.95 \\
15 & 125.5 & 131.099 & 135.351 & 190.107 & 124.54 \\
\hline
\end{tabular}

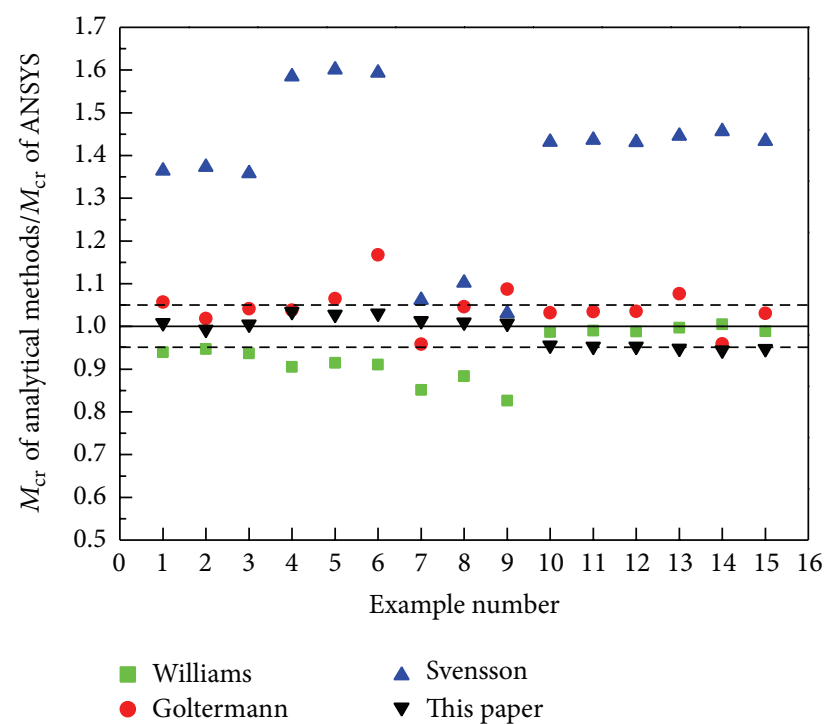

Figure 8: Precision analysis of simplified methods under negative uniform moment.

the length. The critical bending buckling moment is not obviously changed with the increased length of the structural component.

(2) Under triangle bending moment, the critical bending buckling moment is greatly affected by the length; that is, the value decreased quickly when the length increases.

(3) Under uniform negative bending moment, triangle bending moment, and uniform loads, the results yielded by the calculation method in this paper match well the finite element analysis results. The discrepancy is limited within $5 \%$, which validates the accuracy and applicability of this method.

(4) Traditional calculation methods, such as Svensson's method, Williams' method, and Goltermann's method, have considerable deviations from the finite element method.

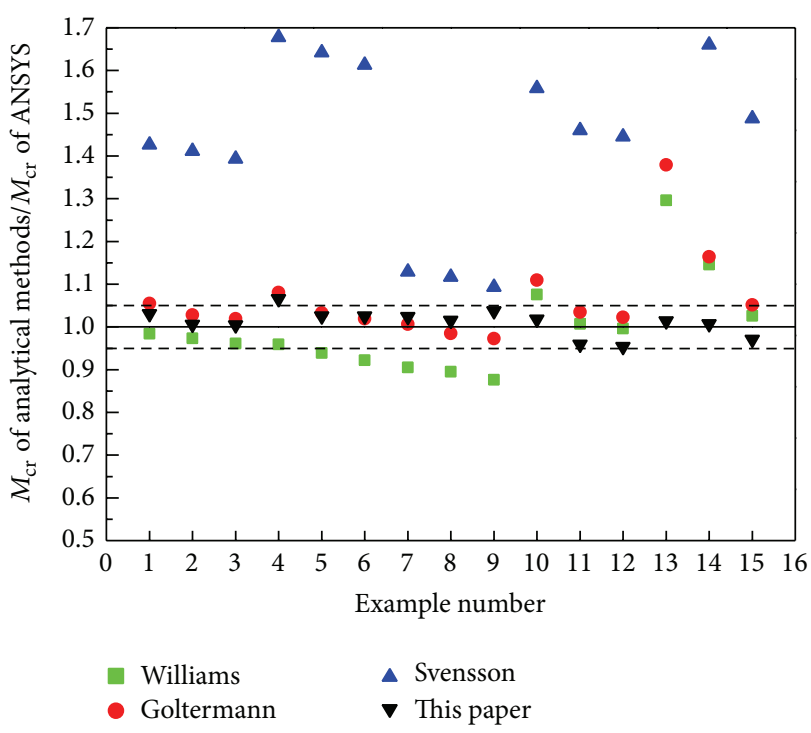

FIGURE 9: Precision analysis of simplified methods under negative triangular moment.

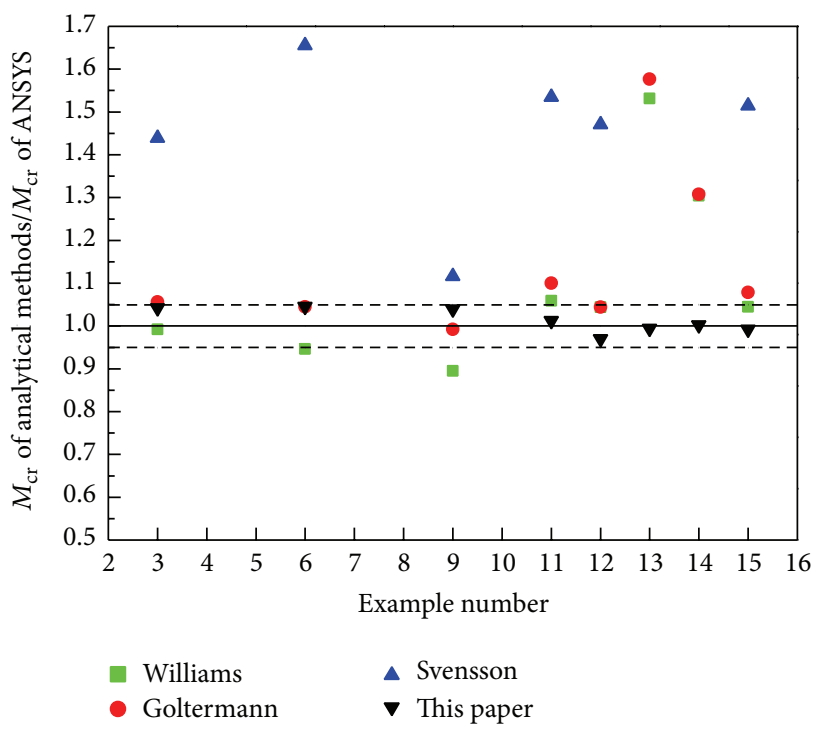

FIGURE 10: Precision analysis of simplified methods under uniformly distributed load.

Therefore, the traditional elastic foundation beam method taking into account the moment gradient needs to be improved. It is also suggested that the constant lateral and torsional restraints in the traditional methods may lead to the relative deviations.

\section{Conclusions}

In this paper, the traditional elastic foundation beam methods are improved by considering the coupling effect of the external loads and the foundation spring constraints. Based on this improvement a simplified calculation method computing the critical buckling loads of steel-concrete composite girders is 
TABLE 6: Critical distortional buckling moment of composite box girder under negative moment.

\begin{tabular}{|c|c|c|c|c|c|c|}
\hline \multirow{3}{*}{$\begin{array}{l}\text { Example } \\
\text { number }\end{array}$} & \multicolumn{6}{|c|}{ Distortional buckling critical moment $M_{\mathrm{cr}} / \mathrm{kN} \cdot \mathrm{m}$} \\
\hline & \multicolumn{2}{|c|}{ Uniform negative bending moment } & \multicolumn{2}{|c|}{ Triangle negative bending moment } & \multicolumn{2}{|c|}{ Uniform load } \\
\hline & ANSYS & $(32)$ & ANSYS & $(32)$ & ANSYS & $(32)$ \\
\hline 1 & 726.05 & 722.14 & 792.36 & 817.41 & 792.82 & 786.74 \\
\hline 2 & 727.14 & 722.14 & 764.67 & 780.46 & 761.22 & 755.31 \\
\hline 3 & 727.97 & 722.14 & 754.92 & 766.16 & 751.46 & 742.62 \\
\hline 4 & 905.93 & 907.22 & 978.11 & 1012.5 & 975.47 & 974.36 \\
\hline 5 & 908.24 & 906.50 & 948.67 & 971.43 & 943.90 & 939.16 \\
\hline 6 & 909.57 & 906.10 & 938.64 & 956.00 & 934.34 & 927.85 \\
\hline 7 & 537.51 & 535.75 & 586.54 & 603.16 & 582.84 & 580.39 \\
\hline 8 & 538.52 & 534.07 & 566.22 & 576.36 & 559.78 & 556.42 \\
\hline 9 & 539.17 & 534.11 & 559.06 & 566.01 & 552.67 & 548.75 \\
\hline 10 & 742.21 & 736.10 & 810.13 & 833.22 & 808.61 & 801.95 \\
\hline 11 & 743.33 & 736.10 & 781.78 & 795.55 & 776.85 & 767.88 \\
\hline 12 & 744.17 & 736.10 & 771.81 & 780.97 & 767.02 & 756.98 \\
\hline 13 & 1253.6 & 1247.9 & 1367.6 & 1412.5 & 1365.9 & 1359.5 \\
\hline 14 & 1255.6 & 1247.9 & 1320.1 & 1348.6 & 1311.4 & 1301.7 \\
\hline 15 & 1260.7 & 1247.9 & 1303.5 & 1323.9 & 1294.7 & 1283.3 \\
\hline
\end{tabular}

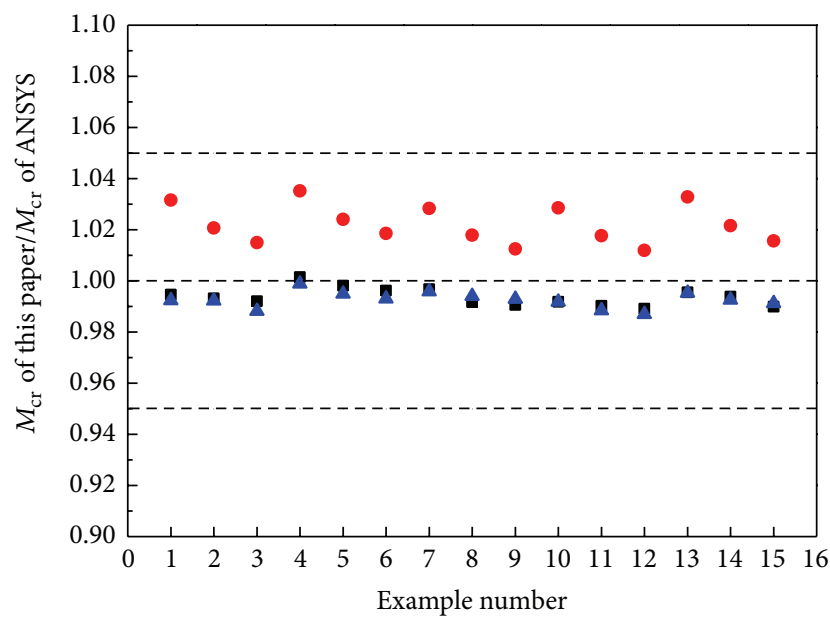

- Negative uniform moment

- Negative triangular moment

- Uniformly distributed load

FIGURE 11: Precision analysis of simplified methods.

developed. The method is compared with various traditional methods. The following conclusions are obtained.

(1) There is a linear coupling relation between both torsional and lateral restraints and vertical loads.

(2) Under uniform negative bending moment, the critical bending buckling moment in the same cross-section of the composite girder is rarely affected by the length. The critical bending buckling moment is not obviously changed with the increased length of the structural component.
(3) Under triangle bending moment, the critical bending buckling is influenced to a great extent by the length; that is, the value decreased quickly when the length increases.

(4) Under uniform negative bending moment, triangle bending moment, and uniform loads, the calculation method proposed in this paper matches well the finite element calculation method. The discrepancy is limited within $5 \%$, which validates the applicability of this method.

\section{Conflict of Interests}

The authors declare that there is no conflict of interests regarding the publication of this paper.

\section{Acknowledgments}

The research described in this paper was financially supported by National Natural Science Foundation of China (51408449 and 51378502) and the Fundamental Research Funds for the Central Universities of China (2014-IV-049).

\section{References}

[1] S. Kim and U. Lee, "Effects of delamination on guided waves in a symmetric laminated composite beam," Mathematical Problems in Engineering, vol. 2014, Article ID 956043, 12 pages, 2014.

[2] D. Champenoy, A. Corfdir, and P. Corfdir, "Calculating the critical buckling force in compressed bottom flanges of steelconcrete composite bridges," European Journal of Environmental and Civil Engineering, vol. 18, no. 3, pp. 271-292, 2014.

[3] T.-H. Yi, H.-N. Li, and M. Gu, "Optimal sensor placement for structural health monitoring based on multiple optimization 
strategies," The Structural Design of Tall and Special Buildings, vol. 20, no. 7, pp. 881-900, 2011.

[4] T.-H. Yi, H.-N. Li, and X.-D. Zhang, "A modified monkey algorithm for optimal sensor placement in structural health monitoring," Smart Materials and Structures, vol. 21, no. 10, Article ID 105033, 2012.

[5] S. Chen and Y. Jia, "Numerical investigation of inelastic buckling of steel-concrete composite beams prestressed with external tendons," Thin-Walled Structures, vol. 48, no. 3, pp. 233$242,2010$.

[6] S. E. Svensson, "Lateral buckling of beams analysed as elastically supported columns subject to a varying axial force," Journal of Constructional Steel Research, vol. 5, no. 3, pp. 179-193, 1985.

[7] F. W. Williams and A. K. Jemah, "Buckling curves for elastically supported columns with varying axial force, to predict lateral buckling of beams," Journal of Constructional Steel Research, vol. 7, no. 2, pp. 133-147, 1987.

[8] P. Goltermann and S. Svensson, "Lateral distortional buckling: predicting elastic critical stress," Journal of Structural Engineering, vol. 114, no. 7, pp. 1606-1625, 1988.

[9] Swedish Institute of Steel Construction, Swedish Code for LightGauge Metal Structures, Swedish Institute of Steel Construction, Stockholm, Sweden, 1982.

[10] British Standards Institution, Code of Practice for Design of Steel Bridge, BS5400: Part 3, BSI, London, UK, 1982.

[11] R. M. Lawson and W. J. Rackham, Design of haunched composite beams in buildings [M.S. thesis], Steel Construction Institution, Ascot, UK, 1989.

[12] L. Jiang, J. Qi, A. Scanlon, and L. Sun, "Distortional and local buckling of steel-concrete composite box-beam," Steel and Composite Structures, vol. 14, no. 3, pp. 243-265, 2013.

[13] J.-H. Ye and W. Chen, "Elastic restrained distortional buckling of steel-concrete composite beams based on elastically supported column method," International Journal of Structural Stability and Dynamics, vol. 13, no. 1, Article ID 1350001, pp. 129, 2013.

[14] W. Chen and J. Ye, "Elastic lateral and restrained distortional buckling of doubly symmetric I-beams," International Journal of Structural Stability and Dynamics, vol. 10, no. 5, pp. 983-1016, 2010.

[15] W.-B. Zhou, L.-Z. Jiang, G.-Q. Shao, and Z.-W. Yu, "Elastic distortional buckling analysis of steel-concrete composite beams in negative moment region," Journal of Central South University (Science and Technology), vol. 43, no. 6, pp. 2316-2323, 2012.

[16] W. B. Zhou, L. Z. Jiang, and Z. W. Yu, "The distortional buckling calculation formula of the steel-concrete composite beams in the negative moment region," Chinese Journal of Computational Mechanics, vol. 29, no. 3, pp. 446-450, 2012.

[17] J. Ye and W. Chen, "Elastic restrained distortional buckling of Isteel-concrete composite beams," Journal of Building Structures, vol. 32, no. 6, pp. 82-91, 2011.

[18] W. Zhou, L. Jiang, Z. Liu et al., "Closed-form solution for shear lag effects of steel-concrete composite box beams considering shear deformation and slip," Journal of Central South University, vol. 19, no. 10, pp. 2976-2982, 2012.

[19] W.-B. Zhou, L.-Z. Jiang, and Z.-W. Yu, "Analysis of free vibration characteristic of steel-concrete composite box-girder considering shear lag and slip," Journal of Central South University, vol. 20, no. 9, pp. 2570-2577, 2013.
[20] W.-B. Zhou, L.-Z. Jiang, Z.-J. Liu et al., "Closed-form solution to thin-walled box girders considering effects of shear deformation and shear lag," Journal of Central South University, vol. 19, no. 9, pp. 2650-2655, 2012.

[21] A. Teodor, A. Guran, and G. Ardbeshir, Theory of Elasticity for Scientists and Engineers, Springer, New York, NY, USA, 2012.

[22] C. Bi and V. Ginting, "Two-grid discontinuous Galerkin method for quasi-linear elliptic problems," Journal of Scientific Computing, vol. 49, no. 3, pp. 311-331, 2011. 


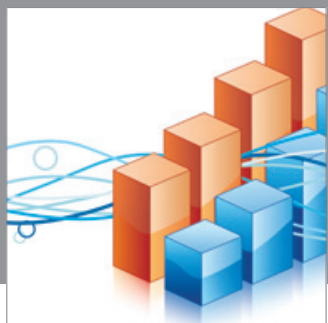

Advances in

Operations Research

mansans

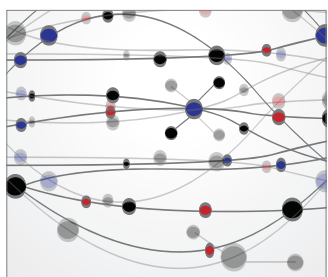

The Scientific World Journal
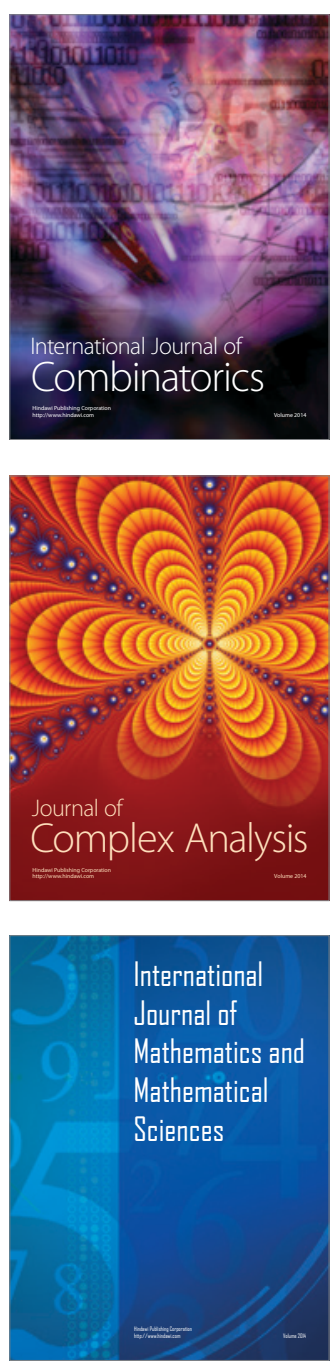
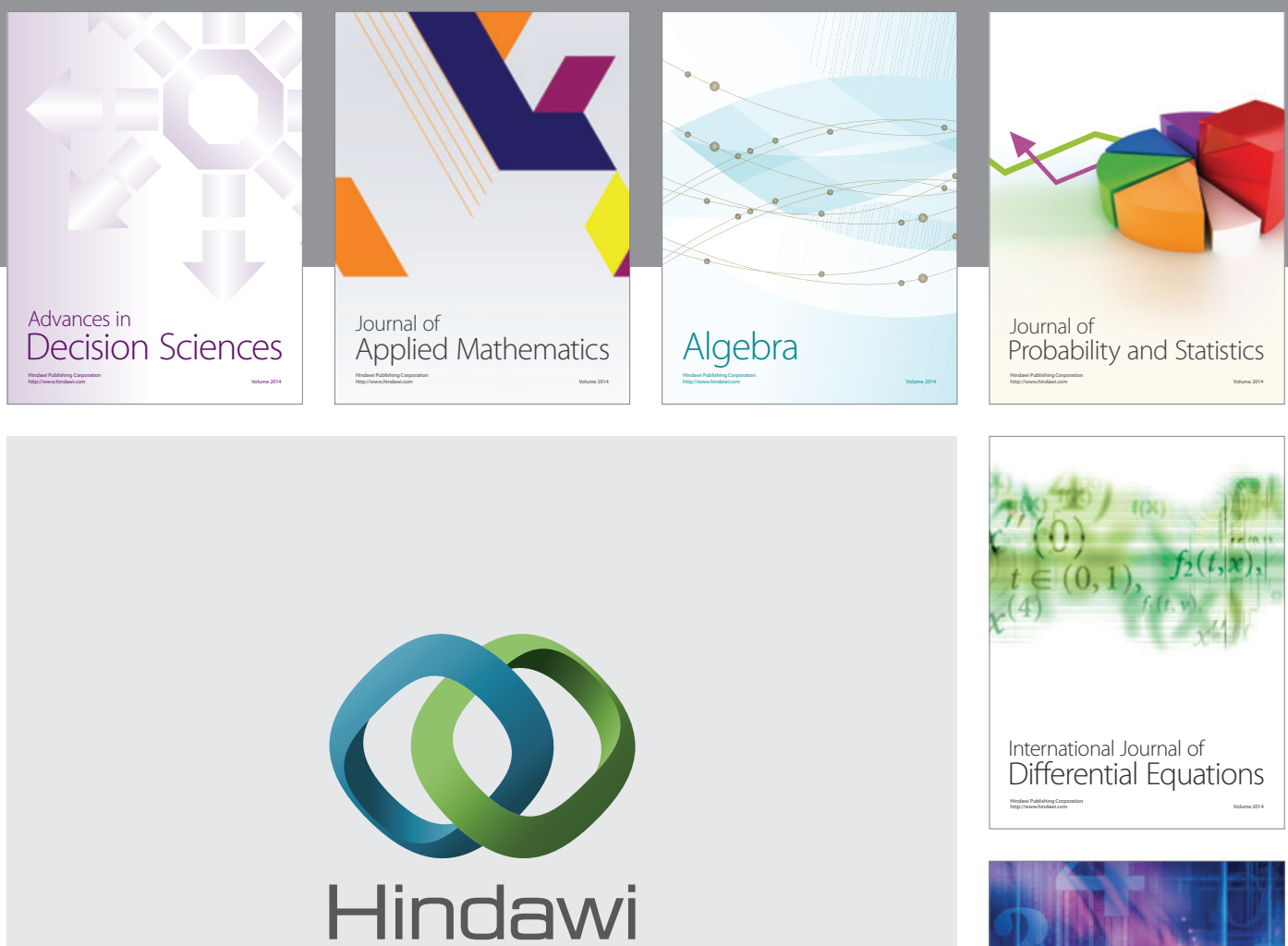

Submit your manuscripts at http://www.hindawi.com
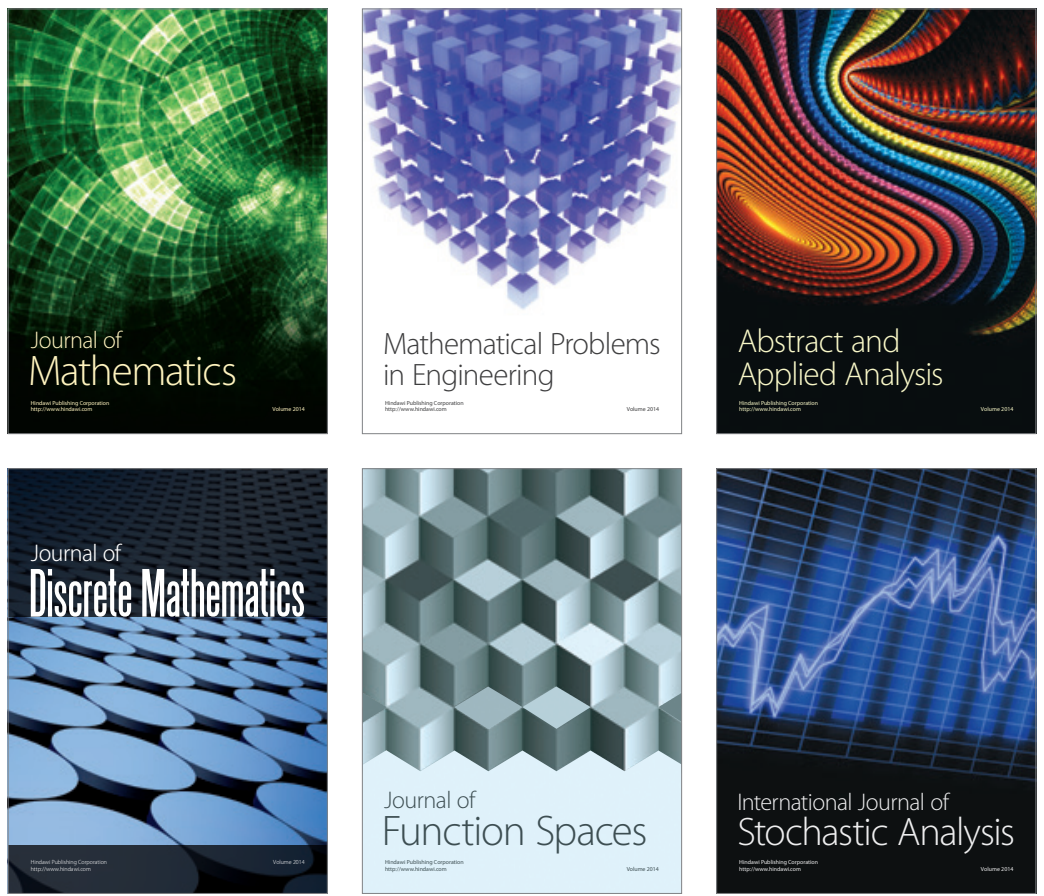

Journal of

Function Spaces

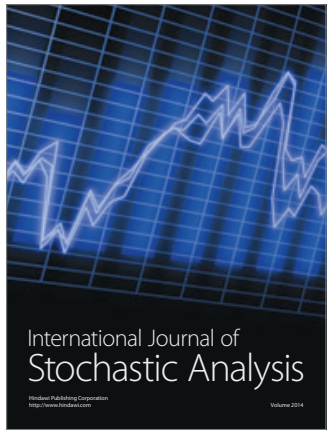

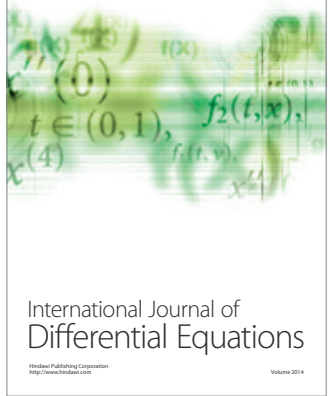
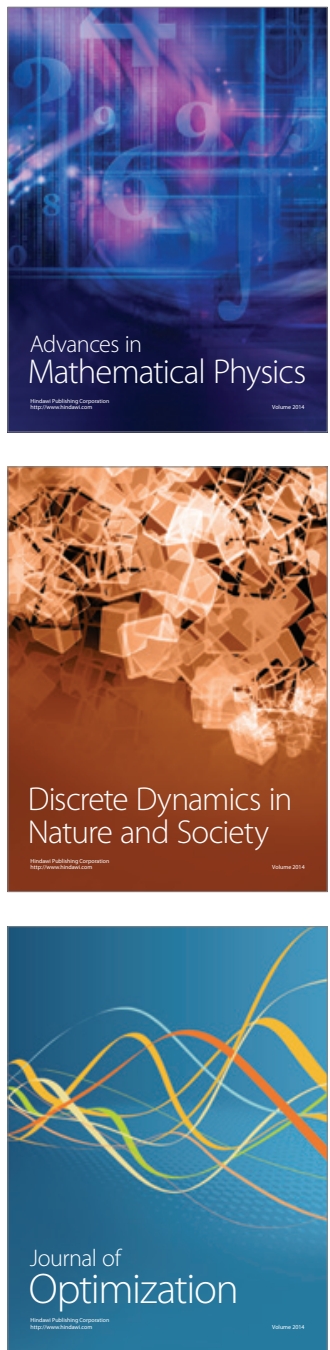